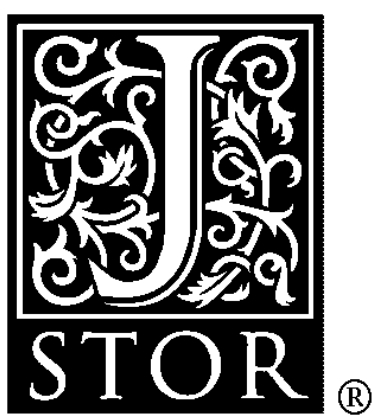

In Search of Homo Economicus: Behavioral Experiments in 15 Small-Scale Societies Author(s): Joseph Henrich, Robert Boyd, Samuel Bowles, Colin Camerer, Ernst Fehr, Herbert Gintis, Richard McElreath

Source: The American Economic Review, Vol. 91, No. 2, Papers and Proceedings of the Hundred Thirteenth Annual Meeting of the American Economic Association (May, 2001), pp. 73-78

Published by: American Economic Association

Stable URL: http://www.jstor.org/stable/2677736

Accessed: 28/08/2008 19:20

Your use of the JSTOR archive indicates your acceptance of JSTOR's Terms and Conditions of Use, available at http://www.jstor.org/page/info/about/policies/terms.jsp. JSTOR's Terms and Conditions of Use provides, in part, that unless you have obtained prior permission, you may not download an entire issue of a journal or multiple copies of articles, and you may use content in the JSTOR archive only for your personal, non-commercial use.

Please contact the publisher regarding any further use of this work. Publisher contact information may be obtained at http://www.jstor.org/action/showPublisher?publisherCode=aea.

Each copy of any part of a JSTOR transmission must contain the same copyright notice that appears on the screen or printed page of such transmission.

JSTOR is a not-for-profit organization founded in 1995 to build trusted digital archives for scholarship. We work with the scholarly community to preserve their work and the materials they rely upon, and to build a common research platform that promotes the discovery and use of these resources. For more information about JSTOR, please contact support@jstor.org. 


\title{
In Search of Homo Economicus: Behavioral Experiments in 15 Small-Scale Societies
}

\author{
By Joseph Henrich, Robert Boyd, Samuel Bowles, Colin Camerer, Ernst Fehr, \\ Herbert Gintis, and Richard McElreath*
}

Recent investigations have uncovered large, consistent deviations from the predictions of the textbook representation of Homo economicus (Alvin E. Roth et al., 1991; Ernst Fehr and Simon Gächter, 2000; Colin Camerer, 2001). One problem appears to lie in economists' canonical assumption that individuals are entirely self-interested: in addition to their own material payoffs, many experimental subjects appear to care about fairness and reciprocity, are willing to change the distribution of material outcomes at personal cost, and are willing to reward those who act in a cooperative manner while punishing those who do not even when these actions are costly to the individual. These deviations from what we will term the canonical model have important consequences for a wide range of economic phenomena, including the optimal design of institutions and contracts, the allocation of property rights, the conditions for successful collective action, the analysis of incomplete contracts, and the persistence of noncompetitive wage premia.

Fundamental questions remain unanswered. Are the deviations from the canonical model evidence of universal patterns of behavior, or do the individual's economic and social environ-

\footnotetext{
* Henrich: School of Business Administration, University of Michigan, Ann Arbor, MI 48109; Boyd and McElreath: Department of Anthropology, University of California at Los Angeles, Los Angeles, CA 90095; Bowles: Department of Economics, University of Massachusetts, Amherst, MA 01003, and Santa Fe Institute; Camerer: Department of Economics, California Institute of Technology, Pasadena, CA 91125; Fehr: Institute for Empirical Research in Economics, University of Zürich, Blümlisalpstrasse 10, CH-8006, Zurich, Switzerland; Gintis: University of Massachusetts, Amherst, MA 01003. The research described in this paper was funded by the MacArthur Foundation's Research Group on the Nature and Origin of Norms and Preferences, directed by Robert Boyd and Herbert Gintis. The field experiments were carried out by Henrich, McElreath, Michael Alvard, Abigail Barr, Jean Ensminger, Francisco Gil-White, Michael Gurven, Kim Hill, Frank Marlowe, John Patton, Natalie Smith, and David Tracer.
}

ments shape behavior? If the latter, which economic and social conditions are involved? Is reciprocal behavior better explained statistically by individuals' attributes such as their sex, age, or relative wealth, or by the attributes of the group to which the individuals belong? Are there cultures that approximate the canonical account of self-regarding behavior?

Existing research cannot answer such questions because virtually all subjects have been university students, and while there are cultural differences among student populations throughout the world, these differences are small compared to the range of all social and cultural environments. To address the above questions, we and our collaborators undertook a large cross-cultural study of behavior in ultimatum, public good, and dictator games. Twelve experienced field researchers, working in 12 countries on five continents, recruited subjects from 15 small-scale societies exhibiting a wide variety of economic and cultural conditions. Our sample consists of three foraging societies, six that practice slash-and-burn horticulture, four nomadic herding groups, and three sedentary, small-scale agriculturalist societies. Our results are described in detail, with extensive ethnographic accounts of the cultures we studied and citations to the relevant literature, in Henrich et al. (2001); an extended overview paper is available online. ${ }^{1}$

We can summarize our results as follows. First, the canonical model is not supported in any society studied. Second, there is considerably more behavioral variability across groups than had been found in previous cross-cultural research, and the canonical model fails in a wider variety of ways than in previous experiments. Third, group-level differences in economic organization and the degree of market

${ }^{1}$ URL: 〈www.santafe.edu〉 
integration explain a substantial portion of the behavioral variation across societies: the higher the degree of market integration and the higher the payoffs to cooperation, the greater the level of cooperation in experimental games. Fourth, individual-level economic and demographic variables do not explain behavior either within or across groups. Fifth, behavior in the experiments is generally consistent with economic patterns of everyday life in these societies.

\section{The Evidence}

Because the ultimatum game (UG) has been conducted throughout the world with student populations and has generated robust violations of the canonical model, we conducted this game in all of our 17 societies. The "proposer" in this game is provisionally assigned an amount equivalent to a day or two's wages in the society and asked to propose an offer to a second person, the "respondent." The respondent may then either accept the offer, in which case the two players receive the proposed amounts, or reject it, in which case the two receive nothing. If both players conform to the canonical model and if this is common knowledge, it is easy to see that the proposer will know that the respondent will accept any positive offer and so will offer the smallest possible amount, which will be accepted.

In most of our field experiments subjects played anonymously, not knowing the identity of the person or persons with whom they were paired. The stakes of most games were denominated in money (though in some cases tobacco or other goods were used). In all cases, we tested prospective participants for their comprehension of the experiment and eliminated any who appeared not to grasp the game.

The systematic deviations from the canonical model in our sample of simple societies can be inferred from Table 1, which lists all groups where UG's were conducted. Contrary to the prediction of the standard model, even the groups with the smallest offers have mean offers greater than 25 percent of stake size. Illustrating our second result (the large variation in mean offers across societies), others, including the Torguud and the Mapuche, offered between 30 percent and 40 percent, while still others, including the Achuar and the Sangu, offered
Table 1-The Ultimatum Game in Small-Scale SOCIETIES

\begin{tabular}{|c|c|c|c|c|c|}
\hline Group & Country & $\begin{array}{l}\text { Mean } \\
\text { offer }^{\mathrm{a}}\end{array}$ & Modes $^{\mathrm{b}}$ & $\begin{array}{l}\text { Rejection } \\
\text { rate }^{\mathrm{c}}\end{array}$ & $\begin{array}{l}\text { Low- } \\
\text { offer } \\
\text { rejection } \\
\text { rate }^{\mathrm{d}}\end{array}$ \\
\hline Machiguenga & Peru & 0.26 & $\begin{array}{c}0.15 / 0.25 \\
(72)\end{array}$ & $\begin{array}{l}0.048 \\
(1 / 21)\end{array}$ & $\begin{array}{c}0.10 \\
(1 / 10)\end{array}$ \\
\hline $\begin{array}{l}\text { Hadza } \\
\qquad \text { (big camp) }\end{array}$ & Tanzania & 0.40 & $\begin{array}{l}0.50 \\
(28)\end{array}$ & $\begin{array}{l}0.19 \\
(5 / 26)\end{array}$ & $\begin{array}{l}0.80 \\
(4 / 5)\end{array}$ \\
\hline $\begin{array}{l}\text { Hadza } \\
\qquad \begin{array}{l}\text { (small } \\
\text { camp) }\end{array}\end{array}$ & Tanzania & $\begin{array}{l}0.27 \\
(38)\end{array}$ & $\begin{array}{c}0.20 \\
(8 / 29)\end{array}$ & $\begin{array}{l}0.28 \\
(5 / 16)\end{array}$ & 0.31 \\
\hline Tsimané & Bolivia & 0.37 & $\begin{array}{c}0.5 / 0.3 / 0.25 \\
(65)\end{array}$ & $\begin{array}{l}0.00 \\
(0 / 70)\end{array}$ & $\begin{array}{l}0.00 \\
(0 / 5)\end{array}$ \\
\hline Quichua & Ecuador & 0.27 & $\begin{array}{l}0.25 \\
(47)\end{array}$ & $\begin{array}{l}0.15 \\
(2 / 13)\end{array}$ & $\begin{array}{l}0.50 \\
(1 / 2)\end{array}$ \\
\hline Torguud & Mongolia & 0.35 & $\begin{array}{l}0.25 \\
(30)\end{array}$ & $\begin{array}{l}0.05 \\
(1 / 20)\end{array}$ & $\begin{array}{l}0.00 \\
(0 / 1)\end{array}$ \\
\hline Khazax & Mongolia & 0.36 & 0.25 & & \\
\hline Mapuche & Chile & 0.34 & $\begin{array}{c}0.50 / 0.33 \\
(46)\end{array}$ & $\begin{array}{l}0.067 \\
(2 / 30)\end{array}$ & $\begin{array}{c}0.2 \\
(2 / 10)\end{array}$ \\
\hline $\mathrm{Au}$ & PNG & 0.43 & $\begin{array}{l}0.3 \\
(33)\end{array}$ & $\begin{array}{l}0.27 \\
(8 / 30)\end{array}$ & $\begin{array}{l}1.00 \\
(1 / 1)\end{array}$ \\
\hline Gnau & PNG & 0.38 & $\begin{array}{l}0.4 \\
(32)\end{array}$ & $\begin{array}{l}0.4 \\
(10 / 25)\end{array}$ & $\begin{array}{l}0.50 \\
(3 / 6)\end{array}$ \\
\hline $\begin{array}{l}\text { Sangu } \\
\text { farmers }\end{array}$ & Tanzania & 0.41 & $\begin{array}{l}0.50 \\
(35)\end{array}$ & $\begin{array}{l}0.25 \\
(5 / 20)\end{array}$ & $\begin{array}{r}1.00 \\
(1 / 1)\end{array}$ \\
\hline $\begin{array}{l}\text { Sangu } \\
\text { herders }\end{array}$ & Tanzania & 0.42 & $\begin{array}{l}0.50 \\
(40)\end{array}$ & $\begin{array}{l}0.05 \\
(1 / 20)\end{array}$ & $\begin{array}{r}1.00 \\
(1 / 1)\end{array}$ \\
\hline $\begin{array}{c}\text { Unresettled } \\
\text { villagers }\end{array}$ & Zimbabwe & 0.41 & $\begin{array}{l}0.50 \\
(56)\end{array}$ & $\begin{array}{l}0.1 \\
(3 / 31)\end{array}$ & $\begin{array}{l}0.33 \\
(2 / 5)\end{array}$ \\
\hline $\begin{array}{l}\text { Resettled } \\
\text { villagers }\end{array}$ & Zimbabwe & 0.45 & $\begin{array}{l}0.50 \\
(70)\end{array}$ & $\begin{array}{c}0.07 \\
(12 / 86)\end{array}$ & $\begin{array}{l}0.57 \\
(4 / 7)\end{array}$ \\
\hline Achuar & Ecuador & 0.42 & $\begin{array}{l}0.50 \\
(36)\end{array}$ & $\begin{array}{l}0.00 \\
(0 / 16)\end{array}$ & $\begin{array}{l}0.00 \\
(0 / 1)\end{array}$ \\
\hline Orma & Kenya & 0.44 & $\begin{array}{l}0.50 \\
(54)\end{array}$ & $\begin{array}{l}0.04 \\
(2 / 56)\end{array}$ & $\begin{array}{l}0.00 \\
(0 / 0)\end{array}$ \\
\hline Aché & Paraguay & 0.51 & $\begin{array}{c}0.50 / 0.40 \\
(75)\end{array}$ & $\begin{array}{l}0.00 \\
(0 / 51)\end{array}$ & $\begin{array}{l}0.00 \\
(0 / 8)\end{array}$ \\
\hline Lamelara $^{\mathrm{e}}$ & Indonesia & 0.58 & $\begin{array}{l}0.50 \\
(63)\end{array}$ & $\begin{array}{l}0.00 \\
(3 / 8)\end{array}$ & $\begin{array}{c}0.00 \\
(4 / 20)\end{array}$ \\
\hline
\end{tabular}

Note: PNG $=$ Papua New Guinea.

a This column shows the mean offer (as a proportion) in the ultimatum game for each society.

b This column shows the modal offer(s), with the percentage of subjects who make modal offers (in parentheses).

${ }^{c}$ The rejection rate (as a proportion), with the actual numbers given in parentheses.

The rejection rate for offers of 20 percent or less, with the actual numbers given in parentheses.

${ }^{\mathrm{e}}$ Includes experimenter-generated low offers.

between 40 percent and 50 percent. Finally, the Aché and the Lamelara had mean offers greater than 50 percent.

These group differences are strikingly large compared to previous cross-cultural work comparing ultimatum-game behavior among university students (Roth et al., 1991). While mean offers in industrial societies are typically close to 44 percent, the mean offers in our sample range from 26 percent to 58 percent. Similarly, while modal offers are consistently 50 percent 
in industrialized societies, our sample modes vary from 15 percent to 50 percent.

As shown in the last two columns of Table 1 , rejections are also much more variable than previously observed. While in industrial societies offers below 20 percent are rejected with probability 0.40 to 0.60 , rejections of low offers are extremely rare among some groups. In other groups, however, we observe substantial rejections rates, including frequent rejections of offers above 50 percent. Among the Achuar, Aché and Tsimané, we observe zero rejections after 16,51 , and 70 proposer offers, respectively. Moreover, while the Aché and Achuar made fairly equitable offers, nearly 50 percent of Tsimané offers were at or below 30 percent, yet all were accepted. Similarly, Machiguenga responders rejected only one offer, despite the fact that over 75 percent of their offers were below 30 percent. At the other end of the rejection scale, Hadza responders rejected 24 percent of all proposer offers and 43 percent of offers at 20 percent and below. Unlike the Hadza, who preferentially rejected low offers, the $\mathrm{Au}$ and Gnau of Papua New Guinea rejected both unfair and hyper-fair (greater than 50 percent) offers with nearly equal frequency.

In experiments with university subjects, offers are generally consistent with incomemaximization, given the distribution of rejections. In our sample, however, in the majority of groups the modal behavior of the proposers is not consistent with expected incomemaximization. In the Tsimané and Aché cases, for instance, there are no rejections of offers below 20 percent, although there were several low offers. The rejection rate for all other offers is also zero. Yet the modal offer in both groups is 50 percent, and the average offers are 37 percent and 51 percent, respectively. Where possible, we used the relationship between the size of the offer and the fraction of rejections to estimate income-maximizing offers for the group in question. In one group, the Hadza proposers approximated the income-maximizing offer quite closely, thus confirming the canonical model; but Hadza responders frequently rejected substantial positive offers, thus violating the canonical model. In all other groups, average offers exceeded the income-maximizing offer, in most cases by a substantial amount.
Data from public-goods games played in seven of these societies also show much greater variation than previously found, and again they exhibit novel deviations from the predictions of the canonical model. Public-goods games ask subjects to contribute to a common pool that will be expanded by the experimenter and then redistributed to all subjects. The canonical prediction is that everyone will free-ride, contributing nothing. Typical distributions of publicgoods game contributions with students have a U-shape, with the mode at contributing nothing, a secondary mode at full cooperation, and mean contribution between 40 percent and 60 percent. By contrast, for instance, the Machiguenga have a mode at contributing nothing, with not a single subject cooperating fully, yielding a mean contribution of 22 percent. Also, the Aché and Tsimané both exhibit inverted distributions, with few or no contributions at full free-riding or full cooperation.

In three dictator games played in three of these societies, groups also deviate both from typical behavior in industrialized societies and the canonical predictions. The dictator game allows the proposer simply to assign some fraction of the stake to a passive second party who receives that amount. Among university students, the distribution of "offers" in the dictator game typically has a mode at zero and a secondary mode at 50/50, while the canonical model predicts that people will give zero. Contrasting with both, the Orma have a mode at 50 percent and a secondary mode at 20 percent. Hadza dictators show a mode at 10 percent. Offers of 0 percent and 50 percent are also popular. Among the Tsimané, there were no zero offers; the mean was 32 percent, and the mode was 25 percent.

\section{What Explains Group-Level Differences?}

The large variations across the different cultural groups suggest that preferences or expectations are affected by group-specific conditions, such as social institutions or cultural fairness norms. The large variance in institutions and norms in our sample allowed us to address this question systematically. Because of space limits we here concentrate on the behavior of proposers in the UG. We rank-ordered the societies along two dimensions: 
(i) Payoffs to cooperation (PC).--How important and how large is a group's payoff from cooperation in economic production?

(ii) Market integration (MI).- - How much do people rely on market exchange in their daily lives?

On the first dimension, payoffs to cooperation, the Machiguenga and Tsimané rank the lowest; they are almost entirely economically independent at the family level and engage rarely in productive activities involving more than members of a family. By contrast, the Lamelara whale-hunters go to sea in large canoes manned by a dozen or more individuals. The rationale for $\mathrm{PC}$ as a predictor of UG offers is that with little cooperative production there will be little necessity to share returns, while those whose livelihood depends on large-scale cooperation like the Lamelara must develop ways of sharing the joint surplus. Thus we might expect that a higher level of PC will increase sharing behavior in the UG. The rationale for market integration as an explanatory variable is that the more frequently people experience market transactions, the more they will also experience abstract sharing principles concerning behaviors toward strangers of which the UG is an example.

We sought to explain group mean UG offers on the basis of these two dimensions of economic structure. In a regression, both PC and MI were highly significant, their (positive) normalized regression coefficients were large in magnitude (about 0.3), and the two measures jointly explained 68 percent of the variance. The impact of PC and MI remains large and robust in an equation predicting individual offers, including individual measures such as sex, age, relative wealth, village population size, stake size, and experimenter experience with the group. Surprisingly, none of these individual level measures was significantly related to offers.

A plausible interpretation of our subjects' behaviors is that, when faced with a novel situation (the experiment), they looked for analogues in their daily experience, asking "What familiar situation is this game like?" and then acted in a way appropriate for the analogous situation. For instance, the hyper-fair UG offers (greater than 50 percent) and the frequent rejections of these offers among the Au and Gnau reflect the culture of gift-giving found in these societies. Among these groups, like many in New Guinea, accepting gifts, even unsolicited ones, commits one to reciprocate at some future time to be determined by the giver. Receipt of large gifts also establishes one in a subordinate position. Consequently, excessively large gifts, especially unsolicited ones, will frequently be refused because of the anxiety about the unspecific strings attached. Similarly the low offers and high rejection rates of the Hadza appear to reflect their reluctant process of sharing (termed "tolerated theft" by a leading ethnographer of the Hadza). While the Hadza extensively share meat, many hunters look for opportunities to avoid sharing and share only because they fear the social consequences of not sharing, in the form of informal social sanctions, gossip, and ostracism. This behavior is apparently transferred to the experimental setting.

Unlike the Hadza, the Aché did not reject low offers, and despite this the vast majority of the Aché (94 percent) made offers above 40 percent of the stake size. This coincides neatly with ethnographic descriptions indicating widespread meat-sharing and cooperation in community projects despite the absence of a fear of punishment in Aché society. Aché hunters, returning home, quietly leave their kill at the edge of camp, often claiming that the hunt was fruitless; their catch is later discovered and collected by others and then meticulously shared among all in the camp. We think it likely that the stake in the game seemed to some of the Aché subjects as analogous to their catch.

The Machiguenga show the lowest cooperation rates in public-good games, reflecting ethnographic descriptions of Machiguenga life, which report little cooperation, exchange, or sharing beyond the family unit. By contrast, Orma experimental subjects quickly dubbed the public-goods experiment a harambee game, referring to the widespread institution of villagelevel voluntary contributions for public-goods projects such as schools or roads. Not surprisingly, they contributed generously (58 percent of the stake), somewhat higher than most U.S. subjects contribute in similar experiments.

\section{Discussion}

Our data indicate that the degree of cooperation, sharing, and punishment exhibited by 
experimental subjects closely corresponds to templates for these behaviors in the subjects' daily lives, and that the substantial variability in experimental behaviors across groups is an expression of the large between-group differences in the structures of social interaction and modes of livelihood. How do we interpret these results?

Some of the variability among groups may be due to variations in implementation. We doubt that this explains the markedly differing behaviors across groups, however, since the experiments were run from identical protocols across groups and were thus as similar in procedures and stake size as we could achieve. Where we could test for experimenter effects we found none. It is possible also that our subjects presumed that their actions would somehow become public. In a good many of our cases, however, subsequent conversations with participants convinced us that this was not the case. Finally, it could be that participants thought they were in a repeated interaction, even though the games we used were clearly one-shot. We do not find this interpretation compelling, however, since there is extensive evidence from experiments in advanced economies that subjects understand the game very well, and those who reject a positive offer in the ultimatum game, when interviewed by the experimenter, typically do not say that they made an error, but rather affirm having goals besides maximizing a monetary payoff.

Why are many subjects willing to share resources and undertake costly reciprocal actions in anonymous one-shot interactions? Bowles et al. (2001) will provide a more extensive response than can be offered here. We suspect that a proximate reason for these behaviors is that situations cue emotional responses which induce the behaviors we have measured. For example, many ultimatumgame responders from advanced societies, when facing a low offer, experience an emotional impulse to hurt the proposer for being unfair, just as the subject might in a real-life bargaining situation. Similarly, the New Guinea responders who rejected hyper-fair offers in the UG may have experienced the same anxiety that emerges when somebody gives them an unsolicited gift in everyday life.

What are the ultimate determinants of our emotions and situation-specific cues? Here long-run evolutionary processes governing the distribution of genes and cultural practices could well have resulted in a substantial fraction of each population being predisposed in certain situations to forgo material payoffs in order to share with others, or to punish unfair actions, as our experimental subjects did. A number of recent contributions have shown that, under conditions that appear to approximate the social and physical environments of early human populations, prosocial behavior can proliferate in a population in which it is initially rare (Bowles et al., 2001).

\section{Conclusion}

While our results do not imply that economists should abandon the rational-actor framework, they do suggest two major revisions. First, the canonical model of the self-interested material payoff-maximizing actor is systematically violated. In all societies studied, UG offers are strictly positive and often substantially in excess of the expected income-maximizing offer, as are contributions in the public-goods game, while rejections of positive offers in some societies occur at a considerable rate. Second, preferences over economic choices are not exogenous as the canonical model would have it, but rather are shaped by the economic and social interactions of everyday life. This result implies that judgments in welfare economics that assume exogenous preferences are questionable, as are predictions of the effects of changing economic policies and institutions that fail to take account of behavioral change. Finally, the connection between experimental behavior and the structure of everyday economic life should provide an important clue in revising the canonical model of individual choice behavior.

\section{REFERENCES}

Bowles, Samuel; Boyd, Richard; Fehr, Ernst and Gintis, Herbert, eds. The foundations of social reciprocity. Unpublished manuscript, University of Massachusetts, 2001.

Camerer, Colin F. Behavioral economics. Princeton, NJ: Princeton University Press, 2001 (forthcoming). 
Fehr, Ernst and Gächter, Simon. "Fairness and Retaliation: The Economics of Reciprocity." Journal of Economic Perspectives, Summer 2000, 14(3), pp. 159-81.

Henrich, Joseph; Boyd, Robert; Bowles, Samuel; Camerer, Colin; Fehr, Ernst; Gintis, Herbert and McElreath, Richard. "Cooperation, Reciprocity and Punishment in Fifteen Small-
Scale Societies." Working paper, Santa Fe Institute, 2001.

$\rightarrow$ Roth, Alvin E.; Prasnikar, Vesna; OkunoFujiwara, Masahiro and Zamir, Shmuel. "Bargaining and Market Behavior in Jerusalem, Ljubljana, Pittsburgh, and Tokyo: An Experimental Study." American Economic Review, December 1991, 81(5), pp. 1068-95. 